\title{
Plant Hydroponic Cultivation: A Support for Biology Research in the Field of Plant-Microbe-Environment Interactions
}

\author{
Haythem Mhadhbi \\ Laboratory of Legumes, \\ Centre of Biotechnology of Borj Cedria (CBBC), Hammam Lif \\ Tunisia
}

\section{Introduction}

Plant production is essentially dependant on culture medium and conditions. Vegetable crops are known to grow in soil which, in natural conditions, acts as a mineral nutrient reservoir, but the soil itself is not essential to plant growth. Plant roots are able to absorb the mineral nutrients of the soil dissolved in water. When the required mineral nutrients are introduced into artificially synthesized medium (case of hydroponic cultivation), soil is no longer required for the plant growth. Hydroponic cultivation is a soil-free technology of vegetable growing. First reports about hydroponic culture date from the seventeenth century. Later, it was reported that in the Second World War, American soldiers grew their own food hydroponically while stationed on barren Pacific islands. Hydroponics was a necessity on Wake Island because there was no soil, and it was prohibitively expensive to airlift in fresh vegetables. Hydroponic cultivation is associated to the most revolutionary future technological projects. Indeed, for "future", NASA Scientists are researching optimization of some factor as light, temperature and carbon dioxide, along with plant species for cultivation on planets like Mars.

Technically, hydroponic cultivation is a method of growing plants using mineral nutrient solutions, in water, without soil. The strict definition of "hydroponic" is referred to liquid systems only. Nevertheless, a more large definition could include cultivation in mineral nutrient solution only or in an inert medium, such as perlite, vermiculite, gravel, mineral wool, coconut husk.... Hydroponic systems may similarly be either closed or open with respectively recycling or non-recycling the nutrient solution.

Hydroponic culture is possibly the most intensive method of crop production in today's agricultural industry, mainly for ornamental plants which could be grown even in the absence of specialized spaces (gardens) restricted because of the demographic pressure, and far from their own natural environment. Indeed, Scandinavian citizen could be able to grow in his house tropical vegetables thanks to hydroponic culture systems. It is highly productive, conservative of water, land and space, and protective of the environment.

The principle advantages of hydroponic vegetable cultivation is a more efficient use of water and fertilizers, minimal use of land area, isolation of the crop from the underlying soil 
which may have problems associated texture and nutrient availability, structure and drainage, disease, salinity... Indeed, in hydroponic medium there are no obstacles for plant roots caused by compact soil structure, which make easier their development and the accessibility of different nutrients.

On the other hand, hydroponic cultivation presents many disadvantages as the high cost of capital and energy inputs required in controlled culture-conditions associated with this mode of plant cultivation. Due to this significantly high cost, successful practical applications (e.g. for food production...) of hydroponic technology are limited to crops of high economic value in specific regions, in country having a sufficient materiel capacities and high degree of competence in plant science and engineering. Unfortunately, these conditions are limited to few countries as the United States, Canada, Europe and Japan that already have no problems with food production. In the developing countries materials and technological conditions did not allow this kind of plant cultivation unless some little exploitation of "exotic" ornamental plants.

Otherwise, hydroponics represents a standard technique in biology research. Indeed this technology of vegetable cultivation enables a more precise control of growth conditions which make easier to study the variables factors or parameters.

The use of Hydroponic cultivation for practical food or ornamental plant production is already detailed in reports and catalogues of societies marketing materials of hydroponic systems. In this chapter, we focus on importance of hydroponic cultivation as a sustainable technology for biological research mainly in studies analyzing plant response to environmental stresses and plant-microbe interactions. Our report will be based essentially on results obtained in the Laboratory of Legumes, Centre of Biotechnology of Borj Cedria, Tunisia, where we analyze the mechanisms, markers and strategy for improvement of legumes production under stressful constraints.

\section{Hydroponic culture systems as source of important biomass production for biological analyses}

Studies are conducted on some legume species (Medicago truncatula, Medicago sativa, Cicer arietinum, Phaseolus vulgaris, Vicia Faba, Lens esculenta...) with the aim to improve yield and tolerance to biotic and abiotic stresses. To reach these aims, multiples analyses should be carried out to dissect response mechanisms, biochemical and molecular markers for selection of efficient genotypes. Plant cultivation was performed under controlled condition (glasshouse, green house) with minimum variation of culture conditions (light, temperature...). Parameters analyzed require an important "clean" biomass for physiological, biochemical and molecular analyses. Two types of hydroponic cultivation were performed: (i) in liquid medium (aeroponic culture) and (ii) with inert support (sterile gravel, sand, perlite, vermiculite...). These hydroponic media allowed a better biomass production mainly for root part. Indeed chickpea (Cicer arietinum), common bean (Phaseolus vulgaris), lucern (Medicago sativa) and barrel medic (Medicago truncatula) plants cultivated in hydroponic media produced root and shoot biomass twice to three time higher than those performed by plants cultivated in soil (table 1). Plants vigor is also better in hydroponic cultivation mode (Figure 1) unless some necrosis that could be revealed at the extremities of old leaves. 


\begin{tabular}{|c|c|c|c|c|c|c|c|c|c|c|c|c|c|c|c|}
\hline & \multicolumn{3}{|c|}{$\begin{array}{l}\text { M. } \\
\text { truncatula }\end{array}$} & \multicolumn{3}{|c|}{ M. sativa } & \multicolumn{3}{|c|}{$\begin{array}{l}\text { Cicer } \\
\text { arietinum }\end{array}$} & \multicolumn{3}{|c|}{$\begin{array}{l}\text { Phaseolus } \\
\text { vulgaris }\end{array}$} & \multicolumn{3}{|c|}{ Vicia faba } \\
\hline & $S$ & $\mathrm{R}$ & $\mathrm{N}$ & $S$ & $\mathrm{R}$ & $\mathrm{N}$ & $S$ & $\mathrm{R}$ & $\mathrm{N}$ & $S$ & $\mathrm{R}$ & $\mathrm{N}$ & $S$ & $\mathrm{R}$ & $\mathrm{N}$ \\
\hline Liquid & $\begin{array}{c}00 \\
10 \\
i\end{array}$ & $\begin{array}{l}\infty \\
-1\end{array}$ & $\begin{array}{l}0,0 \\
10 \\
0 \\
0\end{array}$ & $\begin{array}{l}60 \\
10 \\
+\infty \\
+7\end{array}$ & 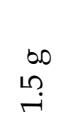 & $\begin{array}{l}\infty \\
\infty \\
0\end{array}$ & ${ }_{0}^{\infty}$ & 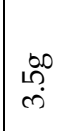 & $\begin{array}{c}00 \\
10 \\
\end{array}$ & $\stackrel{\infty}{\Lambda}$ & $\begin{array}{c}60 \\
N\end{array}$ & $\begin{array}{l}\infty \\
\infty \\
\infty \\
\sim\end{array}$ & $\begin{array}{c}\infty \\
\simeq \\
\ddots\end{array}$ & $\begin{array}{l}0,0 \\
7\end{array}$ & $\begin{array}{l}\infty \\
i n \\
i\end{array}$ \\
\hline Sterile Sand & 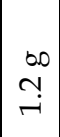 & $\begin{array}{c}\infty \\
10 \\
m \\
0 \\
0\end{array}$ & $\begin{array}{l}\infty 0 \\
\stackrel{10}{?} \\
\stackrel{0}{0}\end{array}$ & $\begin{array}{l}00 \\
0 \\
0 \\
0\end{array}$ & 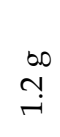 & 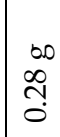 & & & & $\begin{array}{c}\infty \\
N\end{array}$ & $\begin{array}{c}00 \\
0 \\
\end{array}$ & $\begin{array}{c}\infty \\
\infty \\
0 \\
0\end{array}$ & $\mid \begin{array}{c}0 \\
0 \\
0\end{array}$ & $\begin{array}{l}0,0 \\
7\end{array}$ & $\begin{array}{l}\infty \\
N\end{array}$ \\
\hline Sterile Gravel & $\mid \begin{array}{l}\infty \\
0 \\
\vdots \\
0 \\
\infty \\
\infty\end{array}$ & $\begin{array}{c}\infty \\
\vdots \\
\vdots \\
0 \\
10\end{array}$ & & 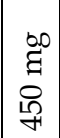 & $\begin{array}{l}\infty \\
\Xi \\
R\end{array}$ & & $\begin{array}{l}\infty \\
\infty \\
\infty\end{array}$ & $\begin{array}{l}0 \\
0 \\
0 \\
0\end{array}$ & 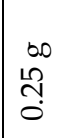 & $\begin{array}{l}60 \\
\sim\end{array}$ & $\begin{array}{l}60 \\
0 \\
0 \\
0\end{array}$ & $\begin{array}{l}\infty \\
+ \\
0\end{array}$ & $\begin{array}{l}60 \\
6\end{array}$ & $\begin{array}{l}\infty \\
\infty\end{array}$ & $\begin{array}{l}000 \\
-1\end{array}$ \\
\hline Perlite & $\begin{array}{l}\infty \\
\stackrel{0}{0}\end{array}$ & $\begin{array}{l}\infty \\
+ \\
\vdots\end{array}$ & 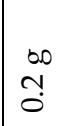 & $\begin{array}{l}00 \\
-1\end{array}$ & $\begin{array}{l}\infty \\
t ! \\
0\end{array}$ & $\begin{array}{l}\infty \\
\text { Na } \\
0\end{array}$ & & & & $\stackrel{0}{\sim}$ & $\mid$\begin{tabular}{c|}
60 \\
$\infty$ \\
0
\end{tabular} & $\begin{array}{c}00 \\
10 \\
0\end{array}$ & & & \\
\hline Perlite/Vermiculite & $\begin{array}{l}\infty \\
\infty \\
\infty \\
0\end{array}$ & $\begin{array}{c}\infty \\
m \\
0 \\
0\end{array}$ & $\begin{array}{l}60 \\
1 \\
0\end{array}$ & $\begin{array}{l}60 \\
\sim \\
\sim \\
-1\end{array}$ & $\begin{array}{l}\infty, 0 \\
\stackrel{0}{0}\end{array}$ & 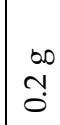 & & & & & & & & & \\
\hline Perlite/Vermiculite/Sand & $\begin{array}{l}\infty \\
-1\end{array}$ & $\begin{array}{l}\infty \\
\infty \\
3 \\
0\end{array}$ & & $\begin{array}{c}60 \\
0 \\
10 \\
7\end{array}$ & 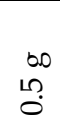 & & & & & & & & & & \\
\hline Soil & $\begin{array}{l}\infty \\
\sim \\
+ \\
-1\end{array}$ & $\begin{array}{l}\infty \\
0 \\
0\end{array}$ & $\begin{array}{l}00 \\
10 \\
? \\
0\end{array}$ & $\begin{array}{c}60 \\
N\end{array}$ & $\begin{array}{l}\infty \\
\infty \\
0 \\
0\end{array}$ & $\begin{array}{l}\infty \\
\stackrel{0}{0} \\
0\end{array}$ & $\begin{array}{l}600 \\
10\end{array}$ & $\begin{array}{l}00 \\
10 \\
10\end{array}$ & $\begin{array}{l}00 \\
-1\end{array}$ & $\begin{array}{l}60 \\
6\end{array}$ & $\mid \begin{array}{c}60 \\
10 \\
\end{array}$ & $\begin{array}{l}\infty \\
\infty \\
0 \\
0\end{array}$ & $\begin{array}{c}\infty \\
\infty\end{array}$ & $\begin{array}{l}\infty \\
N\end{array}$ & חָ \\
\hline Agarose in test tubes & $50 \mathrm{n}$ & & & $70 \mathrm{n}$ & & & & & & & & & & & \\
\hline
\end{tabular}

Table 1. Examples of biomass production levels g/plant and mg/plant (S; Shoots, R; Roots, $\mathrm{N}$; nodules) of some legumes species (Lucern; Medicago sativa, Barrel Medic; Medicago truncatula, Chickpea; Cicer arietinum, Common bean; Phaseolus vulgaris and Faba bean; Vicia $f a b a)$ cultivated under different hydroponic systems compared to soil and in vitro (test-tube) cultivation.

When harvested for analyses, biological material (roots and shoots) issue from hydroponic culture is in healthy state (absence microorganisms and organic substrate adsorbed to roots) which make easier analysis with minimum interference between variables. The hydroponic systems allow homogeneity of the plant sizes. 

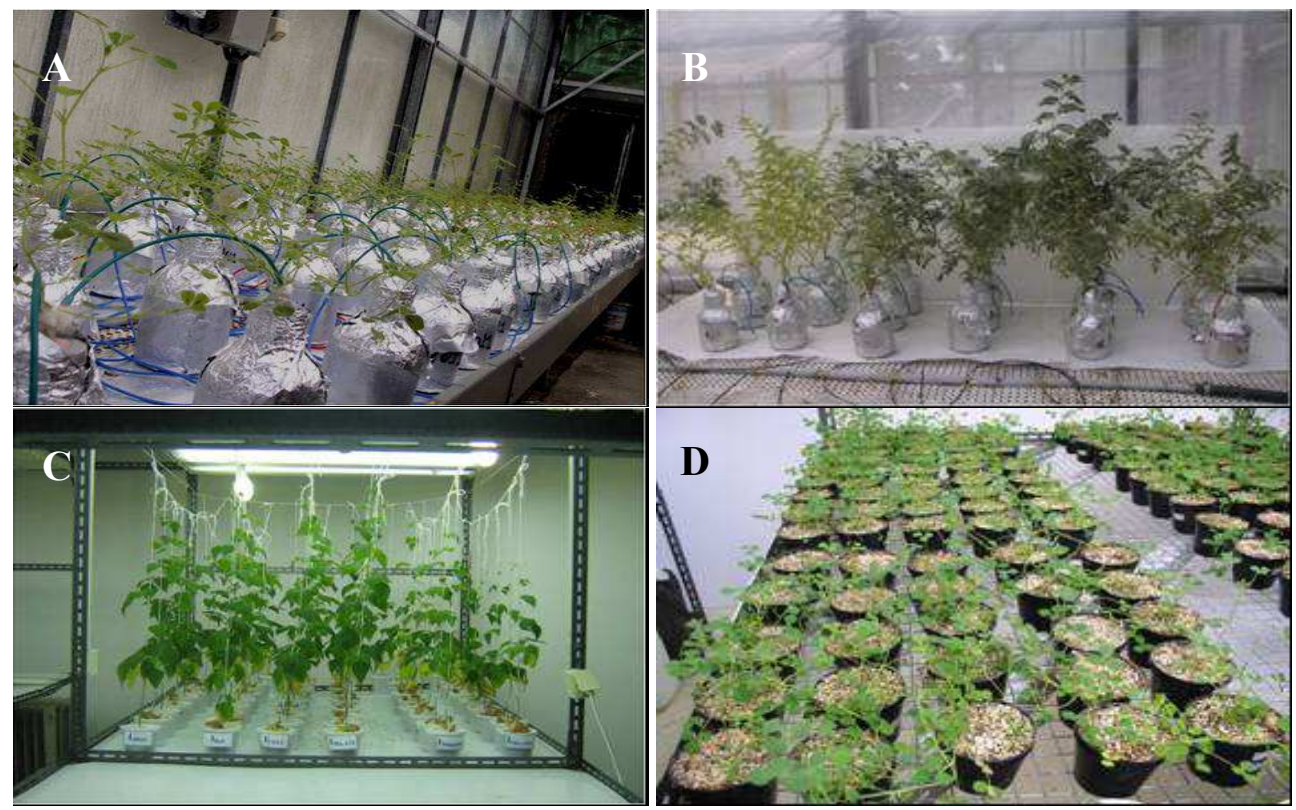

Fig. 1. Culture systems for hydroponic plant cultivation in liquid medium (A: Medicago trunctula, B: Cicer arietinum), sterile gravel (C: Phaseolus vulgaris) and Perlite/vermiculite (D: Medicago truncatula). Plants are grown in glass house with $16 / 8$ photoperiod, $25 / 18^{\circ} \mathrm{C}$ day/night temperature, irrigated with nutrient solution (Vadez et al. 1996, Mhadhbi et al. 2005 ) and aerated with an airflow $400 \mathrm{ml} / \mathrm{min}$ for liquid medium. Plants in the photos are in main flowering stage (68 days M. truncatula, 60 days Cicer arietinum and 45 days Phaseolus vulgaris).

\begin{tabular}{|c|c|c|c|}
\hline & Jemalong (J6) & TN 8.20 & TN 6.18 \\
\hline S. meliloti RCR 2011 & $12.54^{\mathrm{c}}$ & $23.44^{\mathrm{b}}$ & $9.95^{\mathrm{c}}$ \\
\hline S. meliloti KII4 & $14.79^{\mathrm{bc}}$ & $23.00^{\mathrm{b}}$ & $10.20^{\mathrm{c}}$ \\
\hline S. meliloti E4 & $14.80^{\mathrm{bc}}$ & $21.83^{\mathrm{b}}$ & $9.84^{\mathrm{c}}$ \\
\hline S. meliloti TII7 & $17.54^{\mathrm{b}}$ & $23.21^{\mathrm{b}}$ & $12.99^{\mathrm{b}}$ \\
\hline S. meliloti MI4 & $12.29^{\mathrm{c}}$ & $11.9^{\mathrm{c}}$ & $12.00^{\mathrm{b}}$ \\
\hline S. medicae M104 & $21.62^{\mathrm{b}}$ & $19.66^{\mathrm{b}}$ & ND \\
\hline S. medicae A321T & $17.55^{\mathrm{b}}$ & $16.88^{\mathrm{b}}$ & ND \\
\hline S. medicae SII4 & $16.36^{\mathrm{b}}$ & $17.02^{\mathrm{b}}$ & ND \\
\hline S. medicae KI 11a & $15.42^{\mathrm{bc}}$ & $16.56^{\mathrm{b}}$ & ND \\
\hline S. medicae E5 & $14.28^{\mathrm{bc}}$ & $16.30^{\mathrm{b}}$ & ND \\
\hline Nitrogen control & $38.39^{\mathrm{a}}$ & $36.21^{\mathrm{a}}$ & $30.60^{\mathrm{a}}$ \\
\hline Absolute control & $8.46^{\mathrm{d}}$ & $8.57^{\mathrm{d}}$ & $6.61^{\mathrm{d}}$ \\
\hline
\end{tabular}

Table 2. Plant biomass production (mg/plant) of different Barrel Medic (Medicago truncatula) genotypes (one reference Jemalong 6 and two local Tunisian lines TN8.20 and TN6.18) cultivated "in vitro" in test tubes inoculated with different rhizobial strains (Sinorhizobium meliloti and S. medicae) or depended on mineral nitrogen fertilization. Data denoted with different letters are statistically different according to the Duncun multiple range test at $p=0.05$ 
Other types of studies are carried out mainly for wild legumes with an aim to analyze genetic diversity and genotype identification. These kinds of analyses required other culture systems, mainly in the first steps of analysis when an important number of samples are expected. Cultivation on agarose media in Petri dishes or in test-tube allows an important sampling (more than 2000 seedlings per experiment) but it is limiting plant development. Indeed, experiments performed in test-tube for Medicago truncatula plants allow analysis of an important number of genotypes but with a biomass that not reach $50 \mathrm{mg} /$ plant (table 2) however, these plant produce more than $2 \mathrm{~g} /$ plant in hydroponic medium (table 1 ).

Among the different hydroponic media assessed in our experiments, the liquid medium (table 1) associated to artificial aeration $(400 \mathrm{ml} / \mathrm{min} /$ plant) seems been the adequate medium for a maximum plant biomass production, mainly when plant are cultivated in symbiosis with nitrogen fixing bacteria (Mhadhbi et al., 2004, 2005, 2008, 2009, Jebara et al., 2005, 2010). This system presents more advantages "vigorous and clean biological material" due to the absence of support which make easier the physiological, biochemical and molecular analyses performed on root parts.

\section{Control of growth parameters in hydroponic systems}

Analyses performed in biological researches concerning physiological and biochemical metabolisms, proteomic and genomic studies aim the understanding of efficiency and tolerance mechanisms and the selection of plants genotypes. Observations and conclusions performed on these analyses could be precise for the success of selection. Consequently, growth conditions could be the maximum controlled to omit interference with non considered parameters. Indeed, to analyze plant response to biotic agents or environmental constraints, the applied stress could be the only changing factor, which implies the stabilization of the remained factors, as temperature, light intensity, medium acidity, interaction with other microorganisms, equal nutrient provisioning, homogeny plant size.

Plant cultivation in hydroponic media under controlled conditions allow stabilization of these factors since all treatments are under the same condition, in the same support and irrigated with the same nutrient solution. Composition of the nutrient solution could be adjusted according to specific needs of plant species. Indeed, our experience with legumes plants showed that composition of nutrient solution allowing optimal plant growth for some grain legume species (Common bean, Chickpea) (Vadez et al., 1996, Jebara et al., 2001, Mhadhbi et al., 2004, 2008) could be modified for concentration of some elements to be adequate for others legume species (Medicago truncatula, Medicago sativa) (Mhadhbi et al., 2005). Control of mineral elements concentrations and forms could be previously adjusted. Indeed, in our experiments, iron is usually added in its sequestered form (commercial "sequesterne"), nevertheless some species grow better when iron is added as Fe-EDTA form, consequently preliminary experiments could be performed to adjust specific concentrations and form of nutrient elements.

Hydroponic cultivation presents some disadvantages related mainly to the fact that, supports as perlite are preferred by saprophytic fungus. Moreover, when studying drought effect hydroponic media, mainly liquid and artificial-support media, are contested for such analyses. Indeed, the first is far from natural conditions where drought means the absence of water note its presence with the inhibition of its absorption using osmoticum as PEG or Mannitol. In the 
second, it is technically difficult to maintain a stable Field Capacity during long period since vermiculite and mainly perlite are susceptible to evaporation. Among hydroponic media assessed for studying drought stress effect on plant growth, the sterile sand seems been the most adequate. The use of sterile sand as support allow the application of drought constraint and the selection of tolerant genotype or symbioses (Mhadhbi et al., 2011)

\section{Monitoring roots respiration and nodules nitrogen-fixation: Examples of simplicity and effectiveness of gas exchanges analyses in hydroponic systems}

Plants depend on gas exchanges with atmosphere for surviving. Indeed gas flow is determinant factor for main vital processes (photosynthesis and respiration). Measurement of gas $\left(\mathrm{CO}_{2}\right.$ and Oxygen) exchange reflects the healthy state of plants. Photosynthesis is performed in leaves, which make its determination independent of culture system. However, roots respiration depends on support texture. Indeed, monitoring of oxygen flow is influenced by soil texture and structure. In hydroponic systems, mainly aeroponic and systems based on non sandy inert supports allowing easy air circulation (gravel, coconut husk...), the measurement of oxygen flow is a "simple" manipulation using specific electrodes and oxygen monitor related to root atmosphere both in closed of open systems. Jebara et al. (2001) reported differential response of symbiotic common bean (Phaseolus vulgaris) varieties to salt stress based on ability of nodules to maintain respiration under stressful conditions.

A second example of importance of hydroponic system in gas exchange monitoring is measurement of nitrogen fixation within root nodules of legumes (Fabacea) or other symbiotic plants (e.g. Actinorhizale plants). Nitrogen $\left(\mathrm{N}_{2}\right)$ is the main gas in atmosphere $(78 \%)$ and it is essential element for protein and pigment biosynthesis. Nevertheless, among living forms, there are only some microorganisms able to fix atmospheric nitrogen. Some nitrogen fixing bacterial genus communally called Rhizobia are able to establish symbiotic association with legume plants (Fabacea) which enable plants to benefit of fixed nitrogen (For detailed review, Graham \& Vance, 2003, Mhadhbi et al., 2009). Measure of fixed nitrogen is performed by different methods: (i) Khjeldal method which determine the quantity of nitrogen within tissues after plant harvest, there for it is a destructive method, (ii) monitoring fixed nitrogen using N15 isotope which require radioactivity manipulation and so special equipments, care and spaces, (iii) An "In Situ, In Vivo" method using acetylene $\left(\mathrm{C}_{2} \mathrm{H}_{2}\right)$ as structural analogue of molecular nitrogen $\left(\mathrm{N}_{2}\right)$ and the result of reaction is ethylene $\left(\mathrm{C}_{2} \mathrm{H}_{4}\right)$ easily determined using gas chromatograph (Hardy et al., 1968). It is an estimative method with limits due to the inhibition of nitrogense enzyme by acetylene (Minchin et al., 1983) but simple and effective mainly for comparative studies (Mhadhbi et al., 2005, 2008).

The principle of this method is the following: Nodule-bearing roots are incubated in $10 \%$ $\mathrm{C}_{2} \mathrm{H}_{2}$ atmosphere. After " $x$ " min of incubation, the ethylene formation rate was measured using gaseous phase chromatography with Porapak-T column. Statistic replicates of $0.5 \mathrm{ml}$ gas samples were withdrawn from the root atmosphere of each plant, and ethylene production was determined. Pure acetylene and ethylene were used as internal standards.

This method could be performed in soil sample, but error margin is amplified due to the non control of gas diffusion inside soil texture. Aeroponic system is presented as the most adequate system for such kind of measure. 
For both examples (respiration rate and nitrogen fixing capacity estimation), hydroponic culture systems allow simple, safety, non destructive (important for kinetic monitoring of some parameters during plant life cycle) measures, which enable more deep and detailed analyses.

\section{Analysing plant microbe interactions in hydroponic systems}

In the rhizosphere, plants are in continuous interaction with both benefic and pathogenic microorganisms. Thousand years ago, humans discovered some of these interactions and tried to exploit for enhencing food production. Indeed, symbiotic plants as "Lens sp." were domesticated 8000 to 9000 year ago (Graham \& Vance, 2003). The research analyses targeting the exploitation of benefic microorganisms for improvement of plant growth or the protection against the pathogenic ones require a strict control of culture conditions (mainly sterility to ovoid non specific contamination). These practices could be performed in hydroponic systems which, for example, allow the strict control of sterility conditions and even the use of specific synthetic media limiting the possibility of contamination with non desired microorganisms.

\subsection{Symbiotic interactions}

Legume plants (Fabacea) represent best models for studying plant microbe interaction. Indeed, at least $80 \%$ of legume species have the ability to be nodulated by symbiotic atmosphericnitrogen fixing bacteria belonging to the Rhizobiaceae family. This symbiosis lead to formation of a specific organ "nodule" in root parts forming a micro-habitat for nitrogen fixing bacteria. Moreover, legumes are naturally susceptible to biotic agents (pathogenic bacteria and fungus) because of the richness of their roots, leaves and seeds with proteins and other nutritive elements. The most important interaction is the symbiotic interaction that allows the use of abundant atmospheric nitrogen for plant nutrition which decreases the use of mineral fertilizers and consequently reduces the production cost and pollution risks (Graham \& Vance, 2003). Valorization of biological nitrogen fixation for sustainable agriculture is the last steps of long procedure having as a final result the proposition (marketing) of a biological fertilizer efficient in enhancing legume and associated culture production. This is a result of studies of the different interactions between plant and bacteria genotypes and with the ambient environment... In such kind of studies, hydroponic cultivation presents an important number of advantages:

1. An important root surface allowing more infection points and consequently more important nodule number and biomass, and "clean" healthy roots and nodules for biochemical and molecular analyses susceptible to interference of non specific factors (Figure 2).

2. Control of culture conditions mainly omitting contamination, nevertheless precaution to discard non specific interaction should be taken in aerated hydroponic medium mainly when more than one bacterial strain is used for the inoculation.

3. Possibility of monitoring the different steps of plant microbe interaction and different stages of nodule (the main organ of symbiotic interaction) formation (kinetic of nodule apparition), maturation, functioning steps and senescence of nodules.

4. As detailed in section 4, the functioning of symbiosis is estimated through the measure of nitrogenase activity (nitrogenase is a nodular enzyme that catalyze the reduction of molecular atmospheric nitrogen to ammoniac). Hydroponic system allows the "in vivo" 

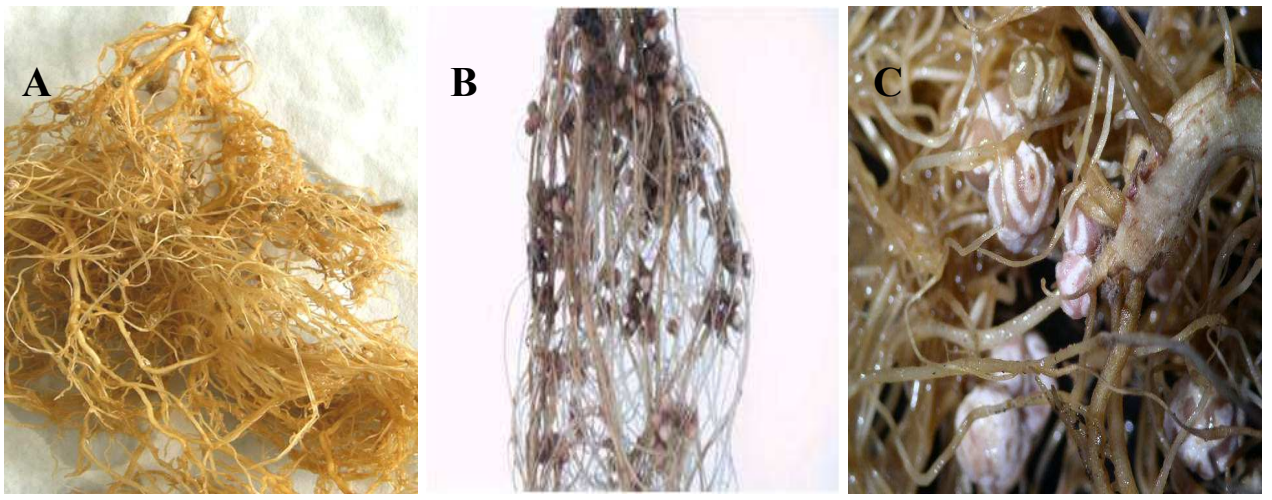

Fig. 2. Roots of some legumes species (Chickpea and common bean) issues from aeroponic cultivation showing an important root biomass development (A) and consequently an enormous number of nodules (B) with healthy and vigorous appearance (C).

measure of nitrogenase activity via the measure of Acetylene Reducing Activity (ARA) (Hardy et al. 1968, Mhadhbi et al. 2004, 2005, 2009). In this context, aeroponic system allows a maximum of control of external parameters. Other functioning indices could be measured in such system as gas exchange, respiration, nodule occupancy using gus A gene transformed bacteria (Mhamdi et al., 2005)

\subsection{Plant pathogens' interactions}

Plants are susceptible to pathogenic microorganisms mainly bacteria and fungus, which cause dramatic effects on cultivated-plant yields reaching the lost of all productionsometimes mainly when environmental conditions are favorable for microorganism development (high temperature and humidity rates). Pathogens attack different parts of and more contested due to its effects on ecosystems' biodiversity and for animal and human health. To use specific pesticide or bio-pesticide we need an exact identification of the pathogen. This identification, mainly at roots level, is not easy to realize in natural conditions since the richness of plant rhizosphere with diverse pathogenic and saprophytic microorganisms that could interfere with the principal agent. Moreover, symptoms of pathogenic attacks as change of root color and root-hair density and quality could be modified by soil quality. As above explained, hydroponic culture allow a maximum control of external parameters (temperature, light, medium sterility...) which enable a precise identification of pathogenic-attack symptoms (Figure 3). Pathogenstrain isolation and identification is more easy and rapid allowing precise and quick intervention.

\section{Limits and disadvantages of hydroponic cultivation}

As mentioned in introduction section, hydroponic cultivation presents multiples limits and disadvantages. The cost of this mode of plant cultivation limits their practice to rich countries (United States, Canada, Europe, Japan...) and discards poor and developing countries which really suffer with environmental constraints, low crop yields and consequent food deficiency. This could exacerbate the lack of equilibrium between the rich 

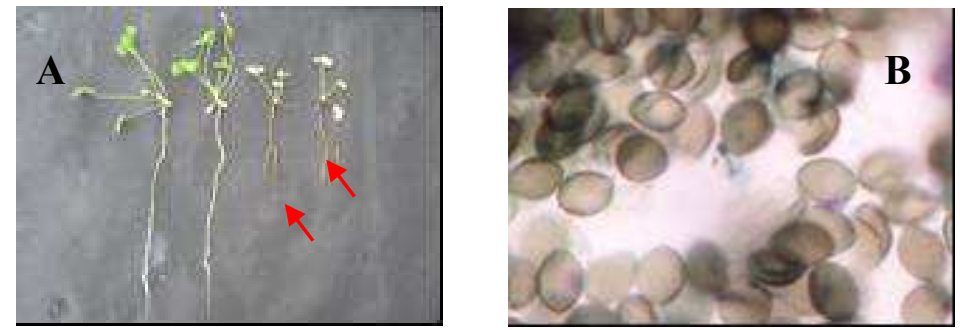

Fig. 3. A. Roots of Medicago truncatula plants (Jemalong 6) inoculated with Phoma medicagenis issues from hydroponic cultivation showing clear symptoms of fungus attack (red arrows).

B. fungi spores developed and isolated from infected roots.

and poor countries. Symptoms of this disequilibrium are now (2011) clearly manifested in countries as Somalia, Kenyaand Ethiopia where famine causes thousand kids' dies per day. In the other hand, in rich counties, prudence of peoples from risks of "biotechnology products" as GMO (genetically modified organisms) on health lead to an orientation to natural and biological product and avoiding products coming from para-natural practices as hydroponic cultivation.

At level of hydroponic cultivation dedicated for biological research, the experiment showed an unequivocal best biomass production for analyses. Nevertheless, a special care must be taken for success of such kind of cultivation mode. Indeed, our experiments showed that concentration of mineral elements added in artificial media is easily changeable in hydroponic systems and plants are very sensitive to these variations. A deleterious effect was revealed due to slight modification of nitrogen or phosphorus concentrations (Mhadhbi et al., 2005). In the hydroponic system the plant growth is totally and strictly dependent on the human control, there is no margin for intrinsic plant adaptation. For aeroponic systems, special care should be taken for an adequate and continuous aeration flow. Indeed, interruption of aeration due to electronic panel during the weekend for example had deleterious effects on experiments, and even if plants recovered from asphyxia, saprophytic contaminations are enhanced by these conditions.

\section{Conclusion}

It could be summarized that hydroponic culture systems represent a suitable support for biological research thanks to some advantages mainly an important clean biomass, a possibility to control external factor influencing experimental conditions even soil structure and texture. Roots and nodules (case of symbiotic plants) biomass production is clearly improved in hydroponic systems mainly aeroponic and those using non-heavy supports (perlite, vermiculite...). It is an artificial system adapted to laboratory conditions (exploitation of limited spaces and overcome soil hard-manipulation). In hydroponic systems we are able to analyze interactions between multiples factors influencing plant growth [e.g. analyzing response of legume plant inoculated with its specific rhizobial partner to abiotic (salinity, drought, cold...) and/or biotic (fungi, bacteria...) constraints]. In the other hand, hydroponic cultivation represents a "new" technology promoting intensive crop production for food and ornamental use. Nevertheless, application of this technique remains restricted to technologically developed countries, which deny hope to 
exploit it in combating poverty in the world. And even in these rich counties an effort is required to convince peoples by differences between hydroponic culture products and those resulting from "non safe" technologies as GMO.

\section{References}

Barber, D. \& Gunn, K. (1974). The effect of mechanical forces on the exudation of organic substrates by the roots of cereal plants grown under sterile conditions. New Phytol. 73: 39-45.

Baylis, A.; Gragopoulou, C. \& Davidson, K. (1994). Effects of Silicon on the Toxicity of Aluminum to Soybean. Comm. Soil Sci. Plant Anal. 25: 537-546.

Bowen, G. \& Roveria, A. (1976). Microbial colonization of plant roots. Annual Reviews of Plant Phytopathology 14: 121-144.

Bugbee, B. \& Salisbury, F. (1985). An evaluation of MES and Amberlite IRC-50 as pH buffers for Nutrient Solution Studies. J. Plant Nutr. 8: 567-583.

Bugbee, B. \& Salisbury, F. (1989). Controlled Environment Crop Production: Hydroponic vs. Lunar Regolith. In: D. Ming and D. Henninger. (eds) Lunar Base Arriculture. Amer. Soc. Agron. Madison, WI.

Chaney, R., \& Coulombe, B. (1982). Effect of phosphate on regulation of Fe-stress in soybean and peanut. J. Plant Nutr. 5: 469-487.

Cherif, M.; Menzies, J.; Ehret, D.; Boganoff, C. \& Belanger, R. (1994). Yield of Cucumber Infected with Phythium aphanidermatum when Grown with Soluble Silicon. Hort Science 29: 896-97.

Glenn, E.P. (1984). Seasonal effects of radiation and temperature on growth of greenhouse lettuce in a high isolation desert environment. Scientific Horticulture 22: 9-21.

Graham, P.H. \& Vance, C.P. (2003). Legumes: importance and constraints to greater use. Plant Physiology 131: 872-877

Graves, C.J. (1983). The nutrient film technique. Horticultural Review 5: 1-44.

Haller, T. \& Stolp, H. (1985). Quantitative estimation of root exudation of the maize plant. Plant and Soil 86: 207-216.

Hoagland, D.R. \& Arnon, D.I. (1950). The Water-culture Method for Growing Plants Without Soil. Cir. 347, California Agricultural Experiment Station, University of California, Berkeley.

Jebara, M.; Drevon, J.J. \& Aouani, M.E. (2001). Effects of hydroponic culture system and $\mathrm{NaCl}$ on interactions between common bean lines and native rhizobia from Tunisian soils. Agronomie 21: 601-605

Jebara, S.; Drevon, J.J. \& Jebara, M. (2010). Modulation of symbiotic efficiency and nodular antioxidant enzyme activities in two Phaseolus vulgaris genotypes under salinity. Acta Physiol. Plant. 32: 925-932 .

Jebara, S.; Jebara, M.; Limam, F. \& Aouani, M.E. (2005). Changes in ascorbate peroxidase, catalase, guaiacol peroxidase and superoxide dismutase activities in common bean (Phaseolus vulgaris) nodules under salt stress. J. Plant Physiol. 162: 929-936.

Jensen, M.H. (1973). Exciting future for sand culture. American Vegetable Grower 21, 11: 33 34,72 .

Jensen, M.H. (1980). Tomorrow's agriculture today. American Vegetable Grower 
Jensen, M.H. (1989). 150,000 acres and rising; Greenhouse agriculture in Korea and Japan. Proc. 10 $0^{\text {th }}$ Annual conference on Hydroponics. Hydroponic Society of America, pp. 79-83.

Ma, J.; Nishimura, K. \& Takahashi, E. (1989). Effect of Silicon on the growth of the Rice Plant at Different Growth Stages. Soil Sci. Plant Nutr. 35: 347-356.

Mhadhbi, H.; Chihaoui, S.; Mhamdi, R.; Mnasri, B.; Jebara, M. \& Mhamdi R. (2011). A highly osmotolerant rhizobial strain confers a better tolerance of nitrogen fixation and an enhanced protective activities to nodules of Phaseolus vulgaris under drought stress. African Journal of Biotechnology, 22: 4555-4563.

Mhadhbi, H.; Djébali, N.; Chihaoui, S.; Jebara, M. \& Mhamdi, R. (2011). Nodule senescence in Medicago truncatula-Sinorhizobium symbiosis under abiotic constraints: Potential mechanisms involved in maintaining nitrogen fixing capacity. Journal of Plant Growth Regulation 30: 480-489

Mhadhbi, H.; Fotopoulos, V.; Djebali, N.; Polidoros, A.N. \& Aouani, M.E. (2009). Behaviours of Medicago truncatula-Sinorhizobium meliloti symbioses under osmotic stress in relation with symbiotic partner input. Effects on nodule functioning and protection. J Agron crop. Sci. 195: 225-231.

Mhadhbi, H.; Fotopoulos, V.; Mylona, P.V.; Jebara, M.; Aouani, M.E. \& Polidoros, A.N. (2011). Antioxidant gene-enzyme responses in Medicago truncatula genotypes with different degree of sensitivity to salinity. Physiologia Plantarum 141: 201-214.

Mhadhbi, H.; Jebara, M.; Limam, F. \& Aouani, M.E. (2004). Rhizobial strain involvement in plant growth, nodule protein composition and antioxidant enzyme activities of chickpea-rhizobia symbioses: modulation by salt stress. Plant Physiol. Biochem. 42: 717-722.

Mhadhbi, H.; Jebara, M.; Limam, F.; Huguet, T. \& Aouani M.E. (2005). Interaction between Medicago truncatula lines and Sinorhizobium meliloti strains for symbiotic efficiency and nodule antioxidant activities. Physiologia Plantarum 124: 4-11.

Mhadhbi, H.; Jebara, M.; Zitoun, A.; Limam, F. \& Aouani, M.E. (2008). Symbiotic effectiveness and response to mannitol-mediated osmotic stress of various chickpea-rhizobia associations. World Journal of Microbiology and Biotechnology 24: 1027-1035.

Minchin, F.R.; Witty, J.F.; Sheehy, J.E. \& Muller, M. (1983). A mayor error in the acetylene reduction assay: decreases in nodular nitrogenase activity under assay conditions. Journal of Experimental Botany 34: 641-649.

Samuels, A.; Glass A.D.M.; Ehret D. \& Menzies J. (1991). Mobility and Deposition of Silicon in Cucumber Plants. Plant Cell and Eenvironnement 14: 485-492.

Smucker, A. (1984). Carbon utilization and losses by plant root systems. p. 27-46. IN: Roots, nutrient and water influx, and plant growth. Am. Soc. Agron. Special publ. 49, Madison, WI.

Trollenier, G. \& Hect-Bucholz, C. (1984). Effect of aeration status of nutrient solution on microorganisms, mucilage and ultrastructure of wheat roots. Plant and Soil 80: 381-390.

Valamis, J. \& Williams, D. (1967). Manganese and Silicon Interaction in the Gramineae. Plant and Soil 28: 131-140. 
Winslow, M. (1992). Silicon, Disease Resistance, and Yield of Rice Genotypes under Upland Cultural Conditions. Crop Sci. 32: 1208-1213. 


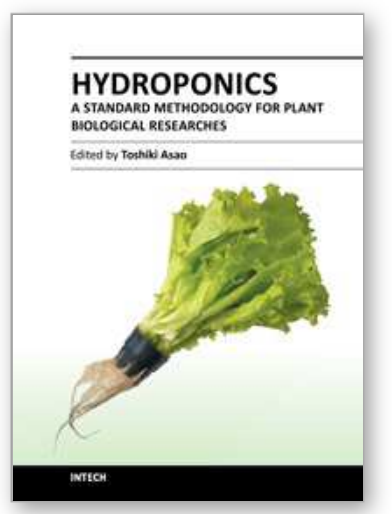

\section{Hydroponics - A Standard Methodology for Plant Biological Researches}

Edited by Dr. Toshiki Asao

ISBN 978-953-51-0386-8

Hard cover, 244 pages

Publisher InTech

Published online 23, March, 2012

Published in print edition March, 2012

Hydroponics-A standard methodology for plant biological researches provides useful information on the requirements and techniques needs to be considered in order to grow crops successfully in hydroponics. The main focuses of this book are preparation of hydroponic nutrient solution, use of this technique for studying biological aspects and environmental controls, and production of vegetables and ornamentals hydroponically. The first chapter of this book takes a general description of nutrient solution used for hydroponics followed by an outline of in vitro hydroponic culture system for vegetables. Detailed descriptions on use of hydroponics in the context of scientific research into plants responses and tolerance to abiotic stresses and on the problems associated with the reuse of culture solution and means to overcome it are included. Some chapters provides information on the role of hydroponic technique in studying plant-microbe-environment interaction and in various aspects of plant biological research, and also understanding of root uptake of nutrients and thereof role of hydroponics in environmental clean-up of toxic and polluting agents. The last two chapters outlined the hydroponic production of cactus and fruit tree seedlings. Leading research works from around the world are brought together in this book to produce a valuable source of reference for teachers, researcher, and advanced students of biological science and crop production.

\section{How to reference}

In order to correctly reference this scholarly work, feel free to copy and paste the following:

Haythem Mhadhbi (2012). Plant Hydroponic Cultivation: A Support for Biology Research in the Field of PlantMicrobe-Environment Interactions, Hydroponics - A Standard Methodology for Plant Biological Researches, Dr. Toshiki Asao (Ed.), ISBN: 978-953-51-0386-8, InTech, Available from:

http://www.intechopen.com/books/hydroponics-a-standard-methodology-for-plant-biological-researches/planthydroponic-cultivation-a-support-for-biological-researches-in-plant-microbe-environment-intera

\section{INTECH}

open science | open minds

\section{InTech Europe}

University Campus STeP Ri

Slavka Krautzeka 83/A

51000 Rijeka, Croatia

Phone: +385 (51) 770447

Fax: +385 (51) 686166

\section{InTech China}

Unit 405, Office Block, Hotel Equatorial Shanghai

No.65, Yan An Road (West), Shanghai, 200040, China 中国上海市延安西路65号上海国际贵都大饭店办公楼 405 单元

Phone: +86-21-62489820

Fax: +86-21-62489821 
www.intechopen.com 
(C) 2012 The Author(s). Licensee IntechOpen. This is an open access article distributed under the terms of the Creative Commons Attribution 3.0 License, which permits unrestricted use, distribution, and reproduction in any medium, provided the original work is properly cited. 